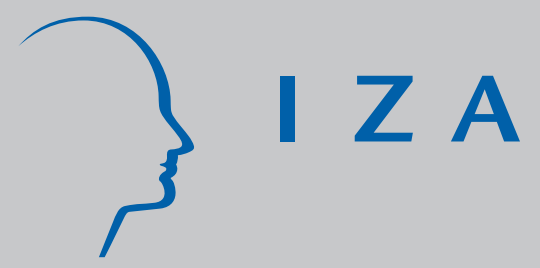

IZA DP No. 1309

Timing Constraints and the Allocation of Time:

The Effects of Changing Shopping Hours Regulations in the Netherlands

J oyce P. J acobsen

Peter Kooreman

September 2004 


\title{
Timing Constraints and the Allocation of Time: The Effects of Changing Shopping Hours Regulations in the Netherlands
}

\author{
Joyce P. Jacobsen \\ Wesleyan University \\ Peter Kooreman \\ University of Groningen \\ and IZA Bonn
}

\section{Discussion Paper No. 1309 \\ September 2004}

\author{
IZA \\ P.O. Box 7240 \\ 53072 Bonn \\ Germany \\ Phone: +49-228-3894-0 \\ Fax: +49-228-3894-180 \\ Email: iza@iza.org
}

\begin{abstract}
Any opinions expressed here are those of the author(s) and not those of the institute. Research disseminated by IZA may include views on policy, but the institute itself takes no institutional policy positions.
\end{abstract}

The Institute for the Study of Labor (IZA) in Bonn is a local and virtual international research center and a place of communication between science, politics and business. IZA is an independent nonprofit company supported by Deutsche Post World Net. The center is associated with the University of Bonn and offers a stimulating research environment through its research networks, research support, and visitors and doctoral programs. IZA engages in (i) original and internationally competitive research in all fields of labor economics, (ii) development of policy concepts, and (iii) dissemination of research results and concepts to the interested public.

IZA Discussion Papers often represent preliminary work and are circulated to encourage discussion. Citation of such a paper should account for its provisional character. A revised version may be available directly from the author. 
IZA Discussion Paper No. 1309

September 2004

\section{ABSTRACT}

\section{Timing Constraints and the Allocation of Time: The Effects of Changing Shopping Hours Regulations in the Netherlands*}

A 1996 change in shopping hours regulations in the Netherlands provides an opportunity to study the effects of timing constraints on total time spent in shopping, working, and other activities as well as the timing of these activities. We develop a simple structural model to make predictions about the effects of imposition and relaxation of a timing constraint on time use patterns, and utilize time diary data from 1995, 1997, 1999, and 2000 to examine time use patterns by demographic group before and after the change. In addition to a change in the timing of shopping, we find a non-negligible increase in the total time spent shopping.

JEL Classification: D12, J22

Keywords: time allocation, labor supply

Corresponding author:

Peter Kooreman

Department of Economics

University of Groningen

P.O. Box 800

9700 AV Groningen

The Netherlands

Email: p.kooreman@eco.rug.nl

\footnotetext{
* We thank Patricia Apps, Dan Hamermesh, Bert Schoonbeek, Adriaan Soetevent, participants at the 2002 and 2003 IZA time use conferences, and a referee for helpful comments. The data used in this paper are available through the Scientific Statistical Agency (http://wsa.magw.nl).
} 


\section{Introduction}

While labor economists have been interested in constraints on paid work for some time, such constraints have been modeled as constraints on the total amount of time spent working rather than as timing constraints, thereby potentially confounding the quantity and timing effects in empirical estimation. In addition, constraints on time use have been considered primarily for market work (cf. Aronsson and Karlsson 1997 re male labour supply), but not for other activities. Children have been considered as a constraint on paid work (cf. Heckman 1988 re children's operating as a constraint requiring wives to perform a certain minimum quantity of household production), as well as a factor requiring parents to expend time (and money) on child care. But again, this relates to the total amount of time spent on activities rather than on timing. Moreover, the exogeneity of this constraint is debatable.

Spurred in part by the greater availability of time use data, some newer papers have explicitly considered timing issues over short time periods (e.g., daily or weekly as opposed to lifecycle issues involving allocation of activities over years). Hamermesh (2002) considers a range of timing phenomena, including synchronization of spouses' work schedules and income effects in reducing work at less pleasant times (i.e., evening and night work). A number of papers in this volume also incorporate short-period timing issues into their analysis.

In this paper we are able to consider a case that extends the analysis of timing issues and escapes a number of the objections that can be brought against other cases. We consider an explicit, exogenous timing constraint on a particular activity, namely shopping hours regulations, and then consider what happens when the constraint is relaxed. Using time diary data, we are able to consider changes that affect not only potentially the total time (measured 
on a weekly basis) devoted to particular activities, but also the way that time may be reallocated across and within days.

Shopping hours regulations have existed throughout time and became particularly constricting in many European countries and in Canada during the 1930s (Rouwendal and Rietveld 1999). While a number of countries have subsequently relaxed their regulations, numerous countries—and local governmental units within countries—continue to constrain the hours during which shops may be open. A number of researchers have considered the effects of such regulations (Huxley 1973, Morrison and Newman 1983, Ferris 1990, Clemenz 1990, 1994, Lanoie, Tanguay, and Vallee 1994, Tanguay, Vallee, and Lanoie 1995, Thum and Weichenrieder 1997, Burda and Weill 1998, Rouwendal and Rietveld 1999). However, none of them have focused on adaptations at the individual level, focusing rather on storelevel reactions such as pricing effects, effects on competition (particularly between smaller and larger stores), and in one case, on insider/outsider reactions in the labor market (Wolter 2001).

In The Netherlands, as of 1996 stores were permitted to stay open from 8 am until 10 pm on weekdays, when before they had to close by $6 \mathrm{pm}$ (with the exception of one weekday, usually Thursday or Friday, when they were allowed to stay open until 9 pm). In addition, as of 1996 stores were permitted to open on Sunday afternoons, although this regulation was subject to modification by local governments, who could limit this. So far the only formal analysis of this regulatory change, a report commissioned by the Dutch government (KPMG 1998), relied on interviewing techniques but did not analyze time diary data to track people's changes in shopping.

Meanwhile time use data have been available on an occasional basis for The Netherlands and other countries for some years and have been utilized by other researchers working in an economic framework (cf. Maassen van den Brink and Groot 1997, Bhat and 
Misra 1999, Yamamoto and Kitamura 1999), but other researchers have not published work analyzing shopping patterns or particular constraints. ${ }^{1}$ No such work is extant for other countries either, although Hamermesh (1996) indicates the potential use of time diary data in the context of considering shopping hours regulations as timing constraints.

Hence our paper fills an interstice between a number of currently unrelated strands of research. We can address the narrow question of how this particular policy change affected individual time use patterns, thereby adding to the literature on shopping regulation effects as well as contributing to the policy evaluation discussion in The Netherlands. But we also consider the larger issue of how one might model timing constraints using fairly detailed time diary data.

In section two we present some general predictions from a simple structural model regarding potential response to the regulatory change. Section three describes the time use data and our use of it to test predictions stemming from the model. Section four shows empirical results, section five provides some discussion, and section six concludes.

\section{A structural model of timing decisions}

In our work below we consider three activities: market work, shopping, and "leisure" (the aggregate of all other activities). Note that even with only three activities, the number of possible weekly time use patterns that can occur in principle with quarter-hour data collection intervals is extremely large: $3^{672}$. The complexity of the analysis would increase greatly with a finer time grid, more activities, multi-person households, data on a monthly or longer basis, and allowing for the possibility of multiple activities per time unit. In an empirical analysis one is therefore bound to limit the level of detail and focus on the aspects that are central to the problem at hand.

\footnotetext{
${ }^{1}$ There is only a small literature applying economic modelling (either theoretical or econometric) to routine (i.e., grocery) shopping; cf. Doti and Sharir (1981) for the first paper in this line; Kan and Fu (1997) consider
} 
In this section we develop a structural model that explains how much time an individual spends weekly on market work, shopping, and leisure, and when: during the day or during the evening. We define "day" as the period from 8 am to $6 \mathrm{pm}$ on Monday through Saturday, and "evening" as the period from $6 \mathrm{pm}$ to $10 \mathrm{pm}$, on Monday through Friday. Thus "day" is roughly defined as the pre-1996 opening times and "evening" as the opening times that were allowed only after the law changed. We do not model timing decisions during the "night" (all hours other than "day" or "evening"). The fraction of people in our sample spending time on market work or shopping during this period is negligibly small in our sample.

We make a number of simplifying assumptions. First, we assume that shopping during the day and during the evening are perfect substitutes; similarly for leisure. While it is of course conceivable (and even likely) that this is not the case for all individuals, the assumption facilitates the separation of the effects of timing constraints from the effects of preferences on timing decisions. Second, we use a simple Cobb-Douglas specification for the utility function. Third, we initially assume that both before and after 1996, market work can be performed only during the day. An important argument for extending the shopping hours has been that it would enable people with a "full-time" job to shop not only on Saturdays (and the single evening during which shops were open under the pre-1996 regime), but also on weekdays. If people could easily work during evenings, the shopping hours constraint could have been accommodated by shopping during the day and shifting some market work to the evening. This was apparently not an option for most people with full-time jobs. Finally, we ignore any effects the regime change may have had on the efficiency of shopping (for example, shops may have become less crowded after the change) or the cost of goods. 
Let $M_{j}, S_{j}$, and $L_{j}$ denote time spent on market work, shopping, and leisure, respectively, during time frame $j, j \in\{D, E\}$. The total time available during the day $(D)$ and during the evening $(E)$ is denoted by $T_{D}$ and $T_{E}$, respectively. The individual can earn a market wage $w$ per hour; non-labor income is denoted by $\mu$, consumption by $y$, and full income by $Y \equiv w\left(T_{D}+T_{E}\right)+\mu$. In the sequel we will use $M \equiv M_{D}+M_{E}, S \equiv S_{D}+S_{E}, L \equiv L_{D}+$ $L_{E}$, and $T \equiv T_{D}+T_{E}$. Note that by assumption $M_{E}=0$, hence $M=M_{D}$.

Consider an individual with preferences represented by the utility function:

$$
U\left(L_{D}, L_{E}, S_{D}, S_{E}, y\right)=\alpha_{l} \ln \left(L_{D}+L_{E}\right)+\alpha_{s} \ln \left(S_{D}+S_{E}\right)+\alpha_{y} \ln (y)
$$

with $\alpha_{l}+\alpha_{s}+\alpha_{y}=1$. Shopping might directly generate utility, or it might merely be an input in the household production process. To separate the two interpretations empirically, direct information on the household products or additional assumptions are required; see Kerkhofs and Kooreman (2003) for a recent analysis of identification problems in household production models. Specification (1) is consistent with both interpretations.

The utility function is maximized subject to the following constraints:

$$
\left\{\begin{aligned}
L_{D}+S_{D}+M_{D} & =T_{D} \\
L_{E}+S_{E} & =T_{E} \\
y & =w M_{D}+\mu \\
0 & \leq L_{D}, S_{D}, M_{D} \leq T_{D} \\
0 & \leq L_{E}, S_{E} \leq T_{E}
\end{aligned}\right.
$$

The constraints characterize the situation after 1996. The impossibility to shop during the evening before 1996 is expressed as the additional, exogenous constraint $S_{E}=0$.

For expositional purposes, we first derive the behavioral equations for the post-change situation and then analyze the effects of imposing the additional constraint $S_{E}=0$. (The actual order of the regimes is immaterial for the analysis.) Pre and post change optimal values will be indicated by superscripts 0 and 1 , respectively. 


\section{Post-change behavior}

If neither of the inequality constraints are binding the model implies that the shares of full income $Y$ spent on consumption, shopping, and leisure are $\alpha_{y} Y, \alpha_{s} Y$, and $\alpha_{l} Y$, respectively, so that

$$
\left\{\begin{aligned}
M_{D}^{1} & =\alpha_{y} Y / w-\mu / w \\
S^{1} & =\alpha_{s} Y / w \\
L^{1} & =\alpha_{l} Y / w
\end{aligned}\right.
$$

(The price of consumption has been normalized to 1.) Note that the maximization problem only yields the optimal total time spent on shopping, as the individual is indifferent between $S_{D}$ and $S_{E}$; similarly for leisure. Given the individual's indifference, it seems natural to assume that, on average, a fraction $S^{1} /\left(S^{1}+L^{1}\right)$ of both the evening time, $T_{E}$, and of the day time that remains after doing market work, $T_{D}-M_{D}^{1}$, is spent on shopping; a fraction $L^{1} /\left(S^{1}\right.$ $\left.+L^{1}\right)$ of both time periods is spent on leisure. Note that (3) implies $S^{1} /\left(S^{1}+L^{1}\right)=\alpha_{s} /\left(\alpha_{s}+\alpha_{l}\right)$ and

$T_{D}-M_{D}^{1}=\left(1-\alpha_{y}\right)(Y / w)-T_{E}$.

Thus

$$
\left\{\begin{array}{l}
M_{D}^{1}=\alpha_{y} Y / w-\mu / w \\
S_{D}^{1}=\frac{S^{1}}{S^{1}+L^{1}} \cdot\left(T_{D}-M_{D}\right)=\alpha_{s}(Y / w)-\alpha_{s} T_{E} /\left(\alpha_{s}+\alpha_{l}\right) \\
L_{D}^{1}=\frac{L^{1}}{S^{1}+L^{1}} \cdot\left(T_{D}-M_{D}\right)=\alpha_{l}(Y / w)-\alpha_{l} T_{E} /\left(\alpha_{s}+\alpha_{l}\right) \\
S_{E}^{1}=\frac{S^{1}}{S^{1}+L^{1}} \cdot T_{E}=\frac{\alpha_{s}}{\alpha_{s}+\alpha_{l}} \cdot T_{E} \\
L_{E}^{1}=\frac{L^{1}}{S^{1}+L^{1}} \cdot T_{E}=\frac{\alpha_{l}}{\alpha_{s}+\alpha_{l}} \cdot T_{E}
\end{array}\right.
$$


If non-labor income is larger than the optimal consumption share, i.e., if $\mu>\alpha_{y} Y$, the individual chooses not to work in the market: $M_{D}^{1}=0$. The optimal division of time and leisure then follows from maximizing:

$$
\alpha_{l} \ln (L)+\alpha_{s} \ln (T-L)
$$

yielding

$$
\left\{\begin{array}{l}
S^{1}=\frac{\alpha_{s}}{\alpha_{s}+\alpha_{l}} T \\
L^{1}=\frac{\alpha_{l}}{\alpha_{s}+\alpha_{l}} T
\end{array}\right.
$$

so that

$$
\left\{\begin{array}{l}
M_{D}^{1}=0 \\
S_{D}^{1}=\frac{S^{1}}{S^{1}+L^{1}} \cdot T_{D}=\frac{\alpha_{s}}{\alpha_{s}+\alpha_{l}} \cdot T_{D} \\
L_{D}^{1}=\frac{L^{1}}{S^{1}+L^{1}} \cdot T_{D}=\frac{\alpha_{l}}{\alpha_{s}+\alpha_{l}} \cdot T_{D} \\
S_{E}^{1}=\frac{S^{1}}{S^{1}+L^{1}} \cdot T_{E}=\frac{\alpha_{s}}{\alpha_{s}+\alpha_{l}} \cdot T_{E} \\
L_{E}^{1}=\frac{L^{1}}{S^{1}+L^{1}} \cdot T_{E}=\frac{\alpha_{l}}{\alpha_{s}+\alpha_{l}} \cdot T_{E}
\end{array}\right.
$$

If non-labor income plus the maximum labor income that can be earned during the day is smaller than the optimal consumption share, i.e., if $\mu+w T_{D}<\alpha_{y} Y$, the individual chooses to work the whole day: $M_{D}^{1}=T_{D}$. The optimal division of time between shopping and leisure then follows from maximizing:

$$
\alpha_{l} \ln \left(L_{E}\right)+\alpha_{s} \ln \left(S_{E}\right)
$$

so that 


$$
\left\{\begin{array}{l}
M_{D}^{1}=T_{D} \\
S_{D}^{1}=0 \\
L_{D}^{1}=0 \\
S_{E}^{1}=\frac{\alpha_{s}}{\alpha_{s}+\alpha_{l}} \cdot T_{E} \\
L_{E}^{1}=\frac{\alpha_{l}}{\alpha_{s}+\alpha_{l}} \cdot T_{E}
\end{array}\right.
$$

(The other inequality constraints are not observed to be binding and are ignored henceforth.)

\section{Pre-change behavior}

We now consider the effects of the additional constraint $S_{E}=0$ in the pre-change regime. Note that the specification of the utility function implies that $S>0$, i.e., individuals cannot function without shopping at all. Combined with $S_{E}=0$, this implies $S_{D}>0$.

If the total amount of time the individual wishes to spend on market work and shopping is smaller than the day time available, i.e., $S^{1}+M_{D}^{1}=\left(\alpha_{s}+\alpha_{y}\right)(Y / w)-(\mu / w)<$ $T_{D}$, the restriction $S_{E}=0$ does not affect the sum of the day and evening time spent on the three activities. However, as leisure is the only possible activity during the evening, some shopping will shift from the evening to the day, with the same amount of leisure time moving in the opposite direction. More precisely,

$$
\left\{\begin{aligned}
M_{D}^{0} & =\alpha_{y}(Y / w)-(\mu / w) \\
S_{D}^{0} & =\alpha_{s}(Y / w) \\
L_{D}^{0} & =T_{D}-M_{D}^{0}-S_{D}^{0}=\alpha_{l}(Y / w)-T_{E} \\
S_{E}^{0} & =0 \\
L_{E}^{0} & =T_{E}
\end{aligned}\right.
$$

Comparing with the post-change expression (with $0<M_{D}^{1}<T_{D}$ ), we find that the shopping (leisure) time that moves from the evening (day) to the day (evening) is $\alpha_{s} T_{E} /\left(\alpha_{s}+\alpha_{y}\right)$. 
If the total time the individual wishes to spend on market work and shopping is larger than the day time available, i.e., $S^{1}+M_{D}^{1}=\left(\alpha_{s}+\alpha_{y}\right)(Y / w)-(\mu / w)>T_{D}$, the restriction $S_{E}$ $=0$ will reduce the total time spent on each of these two activities, and increase leisure time. The optimal division of time between market work and shopping follows from maximizing:

$$
\alpha_{s} \ln \left(S_{D}\right)+\alpha_{y} \ln \left(w\left(T_{D}-S_{D}\right)+\mu\right)
$$

yielding

$$
\left\{\begin{aligned}
M_{D}^{0} & =\frac{\alpha_{y}}{\alpha_{s}+\alpha_{y}}\left(Y / w-T_{E}\right)-(\mu / w) \\
S_{D}^{0} & =\frac{\alpha_{s}}{\alpha_{s}+\alpha_{y}}(Y / w) \\
L_{D}^{0} & =0 \\
S_{D}^{0} & =0 \\
L_{E}^{0} & =T_{E}
\end{aligned}\right.
$$

Note that $\frac{\alpha_{s}}{\alpha_{s}+\alpha_{y}}\left(Y / w-T_{E}\right)<\alpha_{y}(Y / w)$ if $\left(\alpha_{s}+\alpha_{y}\right)(Y / w)-(\mu / w)>T_{D}$.

Thus the structural model predicts that in general there will be no change in the total time spent on working, leisure or shopping. Only the timing of activities will be affected when the restriction to shop during evening hours is released: some shopping time will move from the day to the evening, while the same amount of leisure time moves in the opposite direction. Only for those who work (almost) full time will releasing the shopping hours restriction also affect the total time spent on the various activities: these people will spend more time doing market work (during the day). Their shopping time during the day will decrease, while their total shopping time will increase.

\section{Two-person households}


The model as presented above applies to single persons. In a simple extension of the present model to two-person households, equation (1) could be replaced by

$$
U=\alpha_{l} \ln \left(L_{D}^{1}+L_{E}^{1}+L_{D}^{2}+L_{E}^{2}\right)+\alpha_{S} \ln \left(\mathrm{S}_{D}^{1}+\mathrm{S}_{E}^{1}+\mathrm{S}_{D}^{2}+\mathrm{S}_{E}^{2}\right)+\alpha_{y} \ln (y)
$$

where the superscripts 1 and 2 refer to household members. The utility function is maximized subject to the individual time and inequality constraints and the household budget constraint $y=w^{l} M^{l}{ }_{D}+w^{2} M^{2}{ }_{D}+\mu$.

In this two-person model, the relaxation of the shopping hours constraint is even less likely to affect the total time spent on shopping and market work (aggregated over both spouses), since households will be able to accommodate shopping hours constraints by shifting activities from one person to the other. Only if both partners work (almost) full time might an effect on total time spent on the various activities occur.

In a more elaborate model of two-person households, the total time spent on the various activities could be affected, for example if shopping and leisure of both spouses are complements in the household's utility and/or production functions. However, such an analysis is beyond the scope of the present paper, given the unavailability of matched data on couples.

Note that we might expect that groups with timing constraints related to subcategories within leisure, e.g. household work (including child care), might change the most in timing but again not necessarily increase their total time spent shopping. We have not modeled this explicitly, but might consider that women would be more likely to have such constraints if a greater amount of household production, including some that must be done at particular times of day, falls to them whether by custom or comparative advantage patterns within the household. Indeed, in the U.S. both career and noncareer-oriented women often shop in the 
early evening (Polegato and Zaichkowsky 1994, 1999), implying that if patterns are comparable for women in The Netherlands, the shopping hours constraint might indeed have been binding for many women in The Netherlands. ${ }^{2}$

\section{Evening work}

Another extension would be to allow for evening work, possibly at a different wage rate than work during the day. Again, however, with this extension the shopping hours constraint is even less likely to affect the total time spent on shopping and market work, as individuals would be able to accomodate shopping hours restrictions by moving work from the day to the evening, freeing up time for day shopping.

\section{Data}

We look at the effects of the law change by utilizing cross-section time diary data from directly before, directly after, three years after, and four years after the law change. All four surveys use a random sample from the Dutch population over 12 years of age. Data for 1995 and 2000 are from two SCP surveys ${ }^{3}$, with 3227 people sampled in 1995 and 1813 people in 2000. One individual per household filled out a time diary in fifteen-minute intervals. An entire week of data is available for each person, with over 100 activities coded. Data for 1997 and 1999 are from two CBS surveys ${ }^{4}$, using a comparable sampling methodology, with 4960 people sampled in 1997 and 5641 in $1999 .^{5}$ The main differences from the SCP surveys are that only one day of data is collected per person, and only 32

\footnotetext{
${ }^{2}$ Pashigian and Sun (2000) argue that U.S. stores have responded to women's working more for pay by staying open later, again implying that the shopping hours constraint is binding on at least some women, as women have been working more in The Netherlands as well.

${ }^{3}$ Tijdsbestedingsonderzoek by the Social and Cultural Planning Office of The Netherlands (SCP) in collaboration with other institutions; see http://www.tijdsbesteding.nl and Breedveld (2000).

${ }^{4}$ Tijdsbestedingsonderzoek by Statistics Netherlands, as a part of the Permanent Quality of Life Survey; see http://www.cbs.nl.
} 
activities are coded (and unfortunately no distinction is made between grocery and other shopping). In addition, the 1997 data has only four day-types coded (Monday-Thursday, Friday, Saturday, and Sunday), causing us to aggregate the other years' weekday data to match. In both cases individuals are sampled all year long so the data represent time use patterns over the entire year.

The surveys are relatively comparable in terms of basic demographic composition (to the extent they are different along dimensions for which we stratify below, this will be unimportant; however for looking at the overall figures this is important). We limit each years' sample to persons between the ages of 18 and 65 inclusive so as to incorporate people who are most likely to be choosing actively between all three uses of time (as opposed to being retired or not yet in the labor force). ${ }^{6}$ For this sample, the 1997 and 1999 surveys are almost identical in terms of percentage women (51.4\% and 51.5\% respectively), while the 1995 survey is higher $(55.7 \%)$ and the 2000 survey is much higher $(60.3 \%)$. The percentage of the sample reporting that they are living with a partner (whether marital or cohabitant) varies somewhat between the surveys $\left(72.4 \%, 72.2 \%, 74.5 \%\right.$ and $68.3 \%$ respectively). ${ }^{7} \mathrm{We}$ present results below both for the full subsample, where we control for gender and partnership status (not interacted), and separately for the four subsamples of men and women crossed with partnership status. The mean age for the samples rises slightly, from 38.8 years in 1995 to 39.7 in 1997, 40.5 in 1999, and 41.3 in 2000 . We control in our results below for the effects of age on time use by using age and age squared as controls.

\footnotetext{
${ }^{5}$ The requirement that persons give basic demographic data, including age, gender, and partnership status, reduces our baseline sample sizes to 4947 and 5589 persons respectively.

${ }^{6}$ This leaves us with over three-quarters of the sample in each case: $84.4 \%$, for 2725 persons in $1995 ; 77.0 \%$, for 3811 persons in 1997; 76.8\%, for 4291 persons in 1999; 80.5\%, for 1459 persons in 2000 .

${ }^{7}$ While marital status is also coded for the 1995, 1997, and 1999 samples, the 2000 sample does not differentiate between types of partnerships. Our results comparing 1997 and 1999 to 1995 using marital status rather than partnership status do not indicate that this difference significantly alters our findings relative to those that would relate to marital status.
} 
The CBS surveys start at 6 am on the stated day and run up to 6 am on the following day, while the SCP surveys start at 12 am on the stated day and run up until midnight on the same day. This is not a serious problem for our analysis given that, as assumed in the structural model, it turns out that almost no shopping (or work) occurs in the 12 midnight to 6 am time slot. Therefore we present results regarding daily and weekly time use utilizing only the time after 6 am, and concentrating on the 8 am to $10 \mathrm{pm}$ time period.

Figure 1 illustrates time use using column graphs for the average weekly data for the four samples. In each, the proportion of time in the day-hours interval devoted to leisure, work, and shopping respectively is shown. Starting with the Monday-Thursday composite day and moving through Friday, Saturday, and Sunday, four time periods are shown per day: morning (6-8 am); day (8 am to $6 \mathrm{pm}$ ); evening (6-10 pm); and night (10 pm to 12 midnight). ${ }^{8}$ In all four years, the vast majority of both work and shopping occurs during the day, with a small amount occurring during the evening. ${ }^{9}$ Very little work or shopping occurs on the weekends other than during the daytime on Saturday. The figures show little change in the overall patterns between 1995 and the later years, other than a slight increase in shopping during the evening period on Monday-Thursday. The fraction of time spent on work during the evening is about six times as small as the fraction spent on work during the day. The model's condition that everyone has some shopping time is generally but not completely true: In 1995, nine percent of the sample reports no time shopping during the sample week; in 2000, only seven percent of the sample reports no shopping time. However,

\footnotetext{
${ }^{8}$ A referee suggested that there could be measurement error in the time diaries at points where activities are changing substantially, in particular in the transition period from work to post-work. To test the robustness of our results, we ran alternative specifications in which evening was defined as 7 to $10 \mathrm{pm}$. While this tends to reduce both the percentage of work and the percentage of shopping time that occurs in the evenings (more so for the former category than the latter), our results are qualitatively the same. In particular, we still find a statistically significant increase in shopping during the weekday evenings.

${ }^{9}$ Note that even in the period in which shopping hours constraints are in effect, it is possible to have some shopping during the evening hours. There were occasional exceptions to the rule, occurring mainly in the larger urban areas, allowing for Thursday or Friday night shopping and some Sunday shopping, in the latter case
} 
for the sample as a whole, a nontrivial amount of weekly time is spent in shopping: in 1995, 222 minutes, or 3.7 hours per week; in 2000, 246 minutes, or 4.1 hours per week. Of this total, 60 percent occurs during the day period on a weekday in both 1995 and 2000, while 7.4 percent occurs on a weekday evening in 1995, and 9.0 percent in 2000. A negligible amount occurs during the early morning and late night periods over the whole week (less than one minute in each period per day). The median shopping time is 195 minutes (3.25 hours) in 1995 and 210 minutes (3.5 hours) in $2000 .^{10}$

\section{Results}

We present regression results for the sample as a whole and for the four subsamples of women and men, single and partnered. ${ }^{11}$ In addition, we consider single women and men who work over 35 hours a week. We consider whether the "treatment" and "control" groups have different proportions of time spent in shopping and work (and therefore also leisure).

For each case we show a pooled test result (where the 1997, 1999, and 2000 data are pooled) and also separated test results for 1997,1999 , and 2000 separately as compared to 1995. Rather than creating synthetic weekly data for the 1997 and 1999 samples, we show results separately for the day and evening periods for the four day-types (Monday-Thursday combined, Friday, Saturday, and Sunday). We do calculate below a total time spent in both shopping and work during an average week in each of 1997 and 1999 to compare to the 1995 and 2000 figures. Table 1 shows the results.

particularly during the evenings. In addition, some stores (avondwinkels) during all four sampled years are designed to operate specifically during the evening hours as well as later into the night.

${ }^{10}$ Travel time is coded as time spent shopping if shopping occurs as the use of time right after a period spent in travel.

${ }^{11}$ The regressions contain dummy variables indicating gender and partnership status for the overall regression, and all regressions contain age, age-squared, and dummy variables indicating the year of the data set (with 1995 the omitted category). The dependent variable is the percentage of time in the period spent in the designated activity. 


\section{Single men and women}

Single men show small effects, and are essentially unchanged except for an increase in shopping time on weekday nights and Sunday afternoons in 1999 and an increase in shopping time on Friday and Saturday nights in 2000.

Single women show a consistent pattern of shopping more on Monday through Thursday evenings in all three years. They also shop more on Friday and Saturday evenings and Sunday afternoons in 2000. Single women also increase their worktime on Sunday afternoons by 1999 . If women are more likely to work in retailing, this is consistent with a story in which women work in stores on Sundays. Perhaps it took a longer time for both store owners and shoppers to take advantage of the Sunday afternoon openings, so that this option was not actually used in 1997 . In addition, because the Sunday openings are still regulated at the municipality level, this option is not available in all areas. Even by 2003, 32 percent of municipalitities still did not allow shops to open on Sundays, and only 4 percent of municipalities allowed shops to open all 52 Sundays of the year (Dijkgraaf and Gradus 2003).

\section{Partnered men and women}

Partnered men shop more on Monday through Thursday evenings. They also reduce their daytime work and increase their daytime shopping in 1997 and 1999, a result not predicted by the simple model. They increase their work during Friday and Saturday evenings and Saturday afternoon, although this latter effect occurs significantly only in 1997 and disappears by 1999 .

Like single women, partnered women show a consistent pattern of shopping more on Monday through Thursday evenings in all three years. Partnered women consistently increase their work on Monday through Friday evenings in 1997 and 1999, and during the daytime on Sundays in 1999. Again, this is consistent with a story in which women are more 
likely to work in retail and therefore experience a net increase in employment. ${ }^{12}$ Total retail employment need not necessarily increase (depending on relative staffing and productivity of workers), yet we would expect to see retail employment spread out over a longer daily time period once shopping hours constraints are lifted.

\section{Single men and women with full time jobs}

Table 2 contains results for the subsamples of single men and women who work over 35 hours a week during weekday daytimes. As shown in Table 2, while the pooled sample exhibits a decline in daytime shopping and an increase in weeknight shopping, this is not robust across the subsamples and the years. The total five-day worktime and shopping time totals change only slightly (a nine minute decrease in worktime and a four minute increase in shopping time). This provides mixed support for our hypothesis regarding constrained workers, for while daytime shopping time decreases and nighttime shopping time increases with a small net increase in total shopping time, worktime decreases instead of increasingthe freed-up weekday daytime apparently being taken as nonworktime rather than worktime.

\section{Summary of results}

Hence we see that the empirical results are roughly consistent with our simple structural model, although they also imply potential extensions of the model that would allow us to explain the increase in evening employment for some groups and changes in allocation of work and shopping between household members.

The average change relative to 1995 in total worktime over the week is 6 minutes in 1997, 46 minutes in 1999, and 30 minutes in 2000. The average weekly change in total shopping time is 26 minutes for 1997, 31 minutes for 1999, and 15 minutes for 2000. The

\footnotetext{
${ }^{12}$ This result of increased retail employment was predicted and found empirically by Burda and Weil (1998).
} 
minimum change in total time allocated to each activity is consistent with the prediction of our simple model, with the increase in time spent shopping consistent with the idea that a nonnegligble subset of people are constrained in terms of the total amount of shopping that they would like to be doing under the pre 1996 shopping laws regime. Note the increase in evening work may also imply that the lifting of the shopping hours restrictions also lifts the binding constraint on evening employment, which we did not model explicitly. Single women and men increase both total shopping time ( 25 minutes weekly for women, 9 minutes for men) and total work time (13 minutes weekly for women, 59 minutes for men), as do partnered women (21 minutes of shopping and 68 minutes of work time weekly), while partnered men increase their shopping time ( 25 minutes weekly) but decrease their work time slightly (by 8 minutes on average over the three years). Thus all four groups increase weekly shopping time. Only partnered men reduce their weekly work time while the other three increase weekly work time, but this indicates for all four groups a decline in time spent on all other activities.

We were also interested to see if shopping and work patterns demonstrated any reversion by 2000 , as some more recent discussion in the Dutch press indicates a potential tapering-off of both openness and usage of stores during evening hours (Klok 2002). Indeed, partnered women display a drop in evening shopping by 2000 , while single women had the highest level of evening shopping in 1997, followed by a drop in 1999. However, the aggregate numbers show no drop. There is an increase in Saturday evening shopping by 2000, and Sunday afternoon shopping is significant in 2000 (driven by the single women), which may relate to actually greater use of the Sunday opening times, at least in the large cities, by 2000 . 


\section{Discussion}

Are there other exogenous factors that would tend to change the allocation of time between these three categories that lead us to either over or underattribute changes in time use to the shopping laws changes? In particular, given that we do record some effects, we need to consider simultaneously changing factors that could have caused effects in the direction that we observe.

One factor is that changes may have occurred that would have the effect of either increasing or decreasing the time spent in paid work. For instance, changes in nonlabor income would reduce time spent in paid work, while wages have an ambiguous effect depending on elasticity of labor supply. We use national data to track general trends in hourly earnings and weekly hours worked over this four-year period (Statistics Netherlands; www.cbs.nl, accessed 2/2/04). Over this period, real hourly earnings rise somewhat, by 2.3 percent from 1995 to 1997 and by 8 percent from 1995 to 2000 . The rise is greater for women reporting an earnings rate; 3.8 percent from 1995 to 1997 and 11.5 percent from 1995 to 2000. At the same time, a decline in weekly hours worked occurs, with a drop of 3.1 percent from 1995 to 1997 and a drop of 4.3 percent from 1995 to 2000 . This decline is smaller but continuing for men (2.4 percent lower from 1995 to 1997, 3.5 percent lower from 1995 to 2000) and larger at first for women (4.2 percent lower from 1995 to 1997) and then rising (3.4 percent lower from 1995 to 2000 , for a rise of 0.4 percent from 1997 to 2000). This is consistent with the finding that partnered men in our sample show a drop in time worked over this period. These national trends do not automatically imply more time spent in shopping however, even if the decline in work time could be considered as potentially exogenous to the change caused by shopping hours changes (probably a reasonable assumption). 
One might also wonder if there were changes in substitutes for current forms of goods procurement, for instance increased availability of internet shopping. This might have the effect of increasing or decreasing total time spent in shopping (supposedly it would not be used at all if it did not allow for more efficient shopping) and might have a particularly significant effect in changing the timing of shopping as one can place orders around the clock. Thus shopping hours constraints would be nonbinding on internet shopping, just as they are already nonbinding on catalogue shopping (although not all catalogue outlets allow for around-the-clock order placement). We expect the the effect of internet shopping on time devoted to shopping to be negligible during this period, as internet shopping was in its infancy in 1996. Moreover, the internet has been shown to be more of a substitute for catalog shopping than for store shopping, at least in the US (Ward 2001).

Thus, while we cannot be sure that there are not other changes occurring simultaneously with the shopping laws changes that can either account for the observed changes or are offsetting part of the effects of the shopping laws, the narrowness of the time frame and the absence of major macroeconomic or demographic shocks during this time frame make our story more plausible.

Finally, are there other implications that can be drawn from these time use patterns, in particular any implications regarding overall changes in welfare related to these shopping laws changes? To the extent that the shopping laws change implies increased flexibility in timing, both for people as shoppers and for people as employees, the net overall effect would appear to be positive. ${ }^{13}$

One measure of overall effect that we can calculate is an index of routine, as proposed and implemented by Hamermesh (2003). This index measures the alikeness of scheduling 
from day to day for an individual. Note, however, that while routine is an interesting aspect of time use timing in itself, it can not be straightforwardly interpreted as a welfare measure. As argued by Hamermesh, a low degree of routine is probably inefficient, while a high degree is boring and inherently undesirable. We calculate his index, which uses twelve categories of time use and ranges from 0 to 1 with 0 signifying complete variability, for our 1995 and 2000 data sets, where we have seven days of data for the same person. ${ }^{14}$ Table 3 contains these results, overall and for our four subsamples. Our results are quite similar to Hamermesh's calculations for 1990, using the same time use survey, with higher measures for routine on weekdays than on weekends. ${ }^{15}$ In general, the index shows little change from 1995 to 2000 either overall or for most subgroups, with single women showing a statistically significant drop in routine on weekends and partnered women showing a statistically significant rise in routine on weekends. Hence, we conclude that the effects of the shopping laws change on routine are small.

\section{Conclusion}

Various extensions, more or less straightforward, are suggested by the results presented in this paper. One extension is to consider groups with potentially coordinated production, for instance partnered persons. ${ }^{16}$ We would prefer using matched couple panel data for such a study, which are not readily available. Another possible extension - using the

\footnotetext{
${ }^{13}$ Conclusions regarding the net welfare effects of changing shopping hours regulations are less straightforward once Sunday and evening rest are considered public goods.

${ }^{14}$ Hamermesh (2003) uses the 1990 SCP survey, which is comparable in structure to our data, so we follow his system exactly in calculating an averaged weekday routine index and a weekend index. When comparing two days, for each of the twelve activities and each of the 96 paired time slots $t$, we create the indicator variable $I_{t}=1$ if the activity is the same on both days, 0 otherwise. For the weekend, the index of routine $=\Sigma I_{t} / 96$. For the average across weekdays, because there are ten pairs of weekdays for each respondent, we calculate the index of routine for each pair, sum them up, and divide by ten.

${ }^{15}$ Indeed, the results show a slight rise in the routine index since 1990 (where Hamermesh calculated .587 for weekdays and .458 for weekends). Our subgroup values, while also quite similar, may vary in part because we use partnership rather than marriage and he uses 18 to 69 year olds, while we have an upper age cutoff at 65 .

${ }^{16}$ E.g., Blacklock and Smallwood (1987) model the intrahousehold decision as to who does the routine shopping.
} 
1995 and 2000 surveys - is to look at more detailed categories of time use as well as additional detail regarding weekdays, and weeklong behavior for individuals. For instance, changes in time spent on activities contained within the residual "leisure" category, in particular time spent in nonmarket work, could be considered in more depth. ${ }^{17}$ A broader extension of this type of work would consider other cases where timing constraints exist in addition to or instead of quantity constraints (e.g., schools having set class meeting times; work having set schedules). It would also be interesting to model potential preferences for contiguous blocks of time to be spent in the same activity, potentially so as to reduce the costs of switching from one activity to another, or if productivity increases with duration of activity.

\footnotetext{
${ }^{17}$ In particular, time spent in household production other than shopping could be considered; cf. Jenkins and O'Leary (1995) for a model of determinants of domestic work time.
} 


\section{REFERENCES}

Aronsson, T and Karlsson, N. 1997. "Taxes and Quantity Constraints in a Model of Male Labour Supply in Sweden." Labour 11(1): 201-21.

Bhat, CR and Misra, R. 1999. "Discretionary Activity Time Allocation of Individuals between In-Home and Out-of-Home and between Weekdays and Weekends." Transportation 26(2): 193-209.

Blaylock, JR and Smallwood, DM. 1987. "Intrahousehold Time Allocation: The Case of Grocery Shopping." Journal of Consumer Affairs 21(2): 183-201.

Breedveld, K. (2000), “Time Use Survey 2000”, Social and Cultural Planning Office of The Netherlands.

Burda, M and Weill, P. 1998. "Blue Laws." Working paper.

Clemenz, G. 1990. "Non-sequential Consumer Search and the Consequences of a Deregulation of Trading Hours." European Economic Review 34(7): 1323-37. 1994. "Competition via Shopping Hours: A Case for Regulation?" Journal of Institutional \& Theoretical Economics 150(4): 625-41.

Dijkgraaf, E and Gradus, FHJM. 2003. "Explaining Sunday Shop Policies." OCFEB working paper, Erasmus University.

Doti, JL and Sharir, S. 1981. "Households' Grocery Shopping Behavior in the Short-Run: Theory and Evidence." Economic Inquiry 19(2): 196-208.

Ferris, JS. 1990. "Time, Space, and Shopping: The Regulation of Shopping Hours." Journal of Law Economics \& Organization 6(1): 171-87.

Hamermesh, DS. 1996. "The Timing of Work Time: Evidence from the U.S. and Germany." Konjunkturpolitik 42(1): 1-22.

2002. "Timing, Togetherness, and Time Windfalls." Journal of Population Economics 15(4): 601-23.

2003. "Routine." paper presented at the 2003 IZA Time Use Conference.

Heckman, JJ. 1988. "Time Constraints and Household Demand Functions." Research in Population Economics. 6: 3-14.

Huxley, SJ. 1973. "A Note on the Economics of Retail Trading Hours." Economic Analysis \& Policy 4(1): 17-22.

Jenkins, SP and O'Leary, NC. 1995. "Modelling Domestic Work Time.” Journal of Population Economics 8(3): 265-79.

Kan, K and Fu, T. 1997. "Analysis of Housewives' Grocery Shopping Behavior in Taiwan: An Application of the Poisson Switching Regression." Journal of Agricultural \& Applied Economics 29(2): 397-407.

Kerkhofs, M and Kooreman, P. 2003. "Identification and Estimation of a Class of Household Production Models." Journal of Applied Econometrics 18: 337-369.

Klok, P. 2002. "Winkels Weer Gewoon Om Zes Uur Dicht (Shops just close at six again)" De Volkskrant (5 Feb.): 1, 15.

KPMG Bureau voor Economische Argumentatie en GFK Nederland. 1998. "Effecten van de Winkeltijdenwet. (Effects of the Shopping Time Act)"

Lanoie, P; Tanguay, GA, and Vallee, L. 1994. "Short-Term Impact of Shopping-Hour Deregulation: Welfare Implications and Policy Analysis." Canadian Public PolicyAnalyse de Politiques 20(2): 177-88.

Maassen van den Brink, H and Groot, W. 1997. "A Household Production Model of Paid Labor, Household Work and Child Care." De Economist 145(3): 325-43.

Morrison, SA and Newman, RJ. 1983. "Hours of Operation Restrictions and Competition among Retail Firms.” Economic Inquiry 21(1): 107-14. 
Pashigian, BP and Sun, J. 2000. "Firm Responses to Inequality and the Cost of Time." University of Chicago Center for the Study of the Economy and the State Working Paper.

Polegato, R and Zaichkowsky, JL. 1994. "Family Food Shopping: Strategies Used by Husbands and Wives." Journal of Consumer Affairs 28(2): 278-99. 1999. "Food Shopping Profiles of Career-Oriented, Income-Oriented, and At-Home Wives." Journal of Consumer Affairs 33(1): 110-33.

Rouwendal, J and Rietveld, P. 1999. "Prices and Opening Hours in the Retail Sector: Welfare Effects of Restrictions on Opening Hours." Environment \& Planning 31(11): 200316.

Tanguay, G; Vallee, L; and Lanoie, P. 1995. "Shopping Hours and Price Levels in the Retailing Industry: A Theoretical and Empirical Analysis." Economic Inquiry 33(3): 516-24.

Thum, M and Weichenrieder, A. 1997. “'Dinkies' and Housewives: The Regulation of Shopping Hours." Kyklos 50(4): 539-59.

Ward, MR. 2001. "Will Online Shopping Compete More with Traditional Retailing or Catalog Shopping?" NETNOMICS: Economic Research \& Electronic Networking 3(2): 103-17.

Wolter, SC. 2001. "Opposition of Retail Sales Staff to Shopping Hours Liberalization: An Application of the Insider-Outsider Theory." International Journal of Manpower 22(5): 445-56.

Yamamoto, T and Kitamura, R. 1999. "An Analysis of Time Allocation to In-Home and Outof-Home Discretionary Activities across Working Days and Non-working Days." Transportation 26(2): 211-30. 
Figure 1: Time use across days and time periods within days (left to right: 6-8 am, 8 am-6 pm, 6-10 pm, 10-12 pm for Mon-Thurs., Friday, Saturday, Sunday)

1995 Time Use Patterns

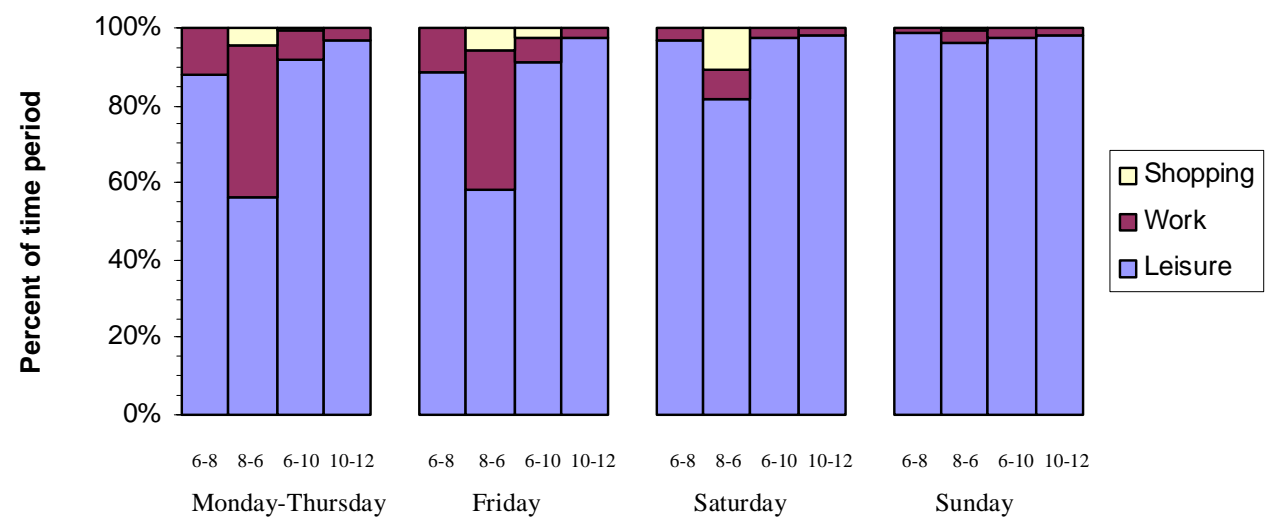

1997 Time Use Patterns

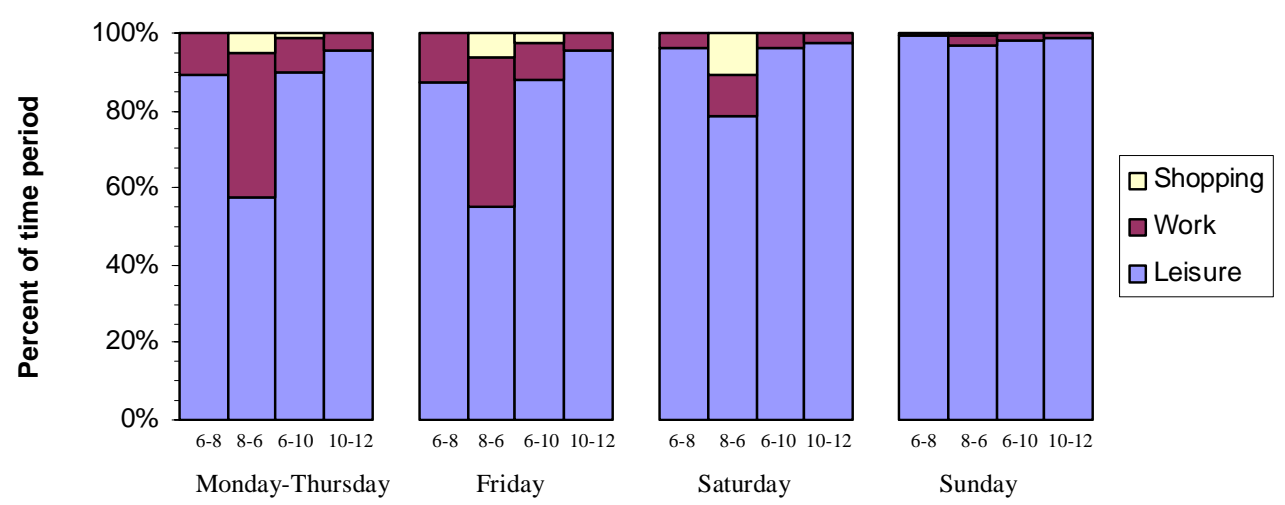


1999 Time Use Patterns
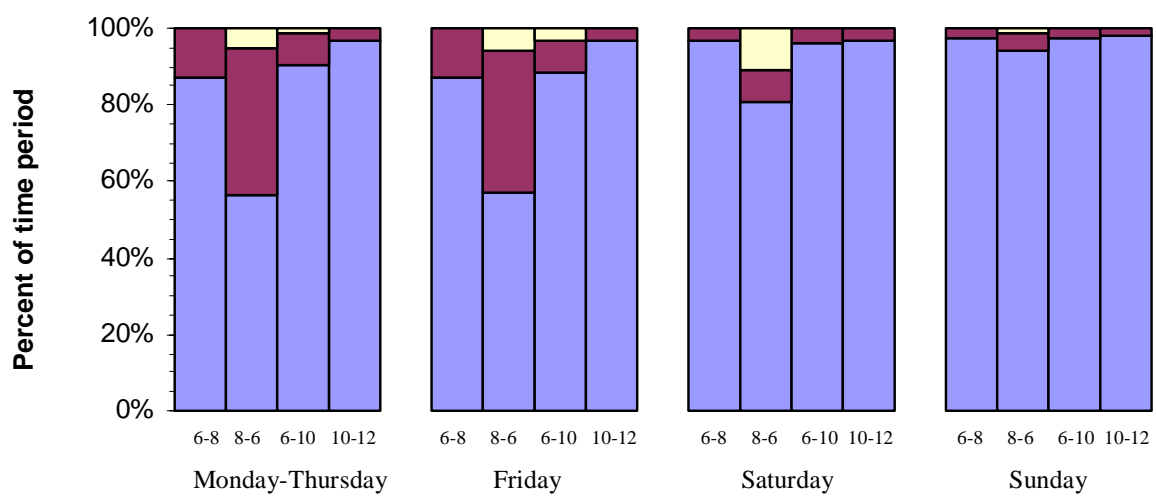

$\square$ Shopping

$\square$ Work

$\square$ Leisure

2000 Time Use Patterns

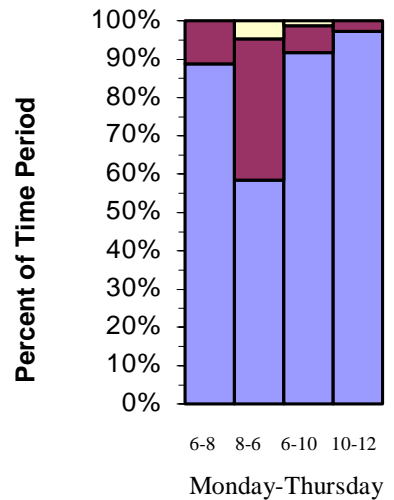

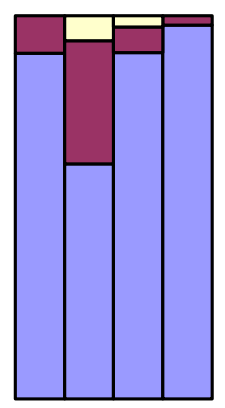

6-8 $\quad 8-6 \quad 6-10 \quad 10-12$

Friday

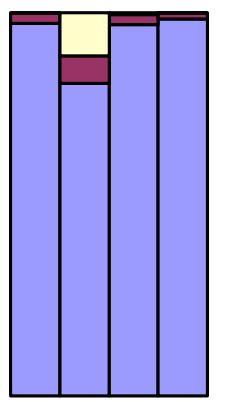

6-8 $\quad 8-6 \quad 6-10 \quad 10-12$ Saturday

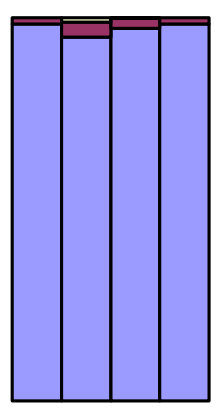

$\square$ Shopping

$\square$ Work

$\square$ Leisure $\begin{array}{llll}6-8 & 8-6 & 6-10 & 10-12\end{array}$

Sunday 


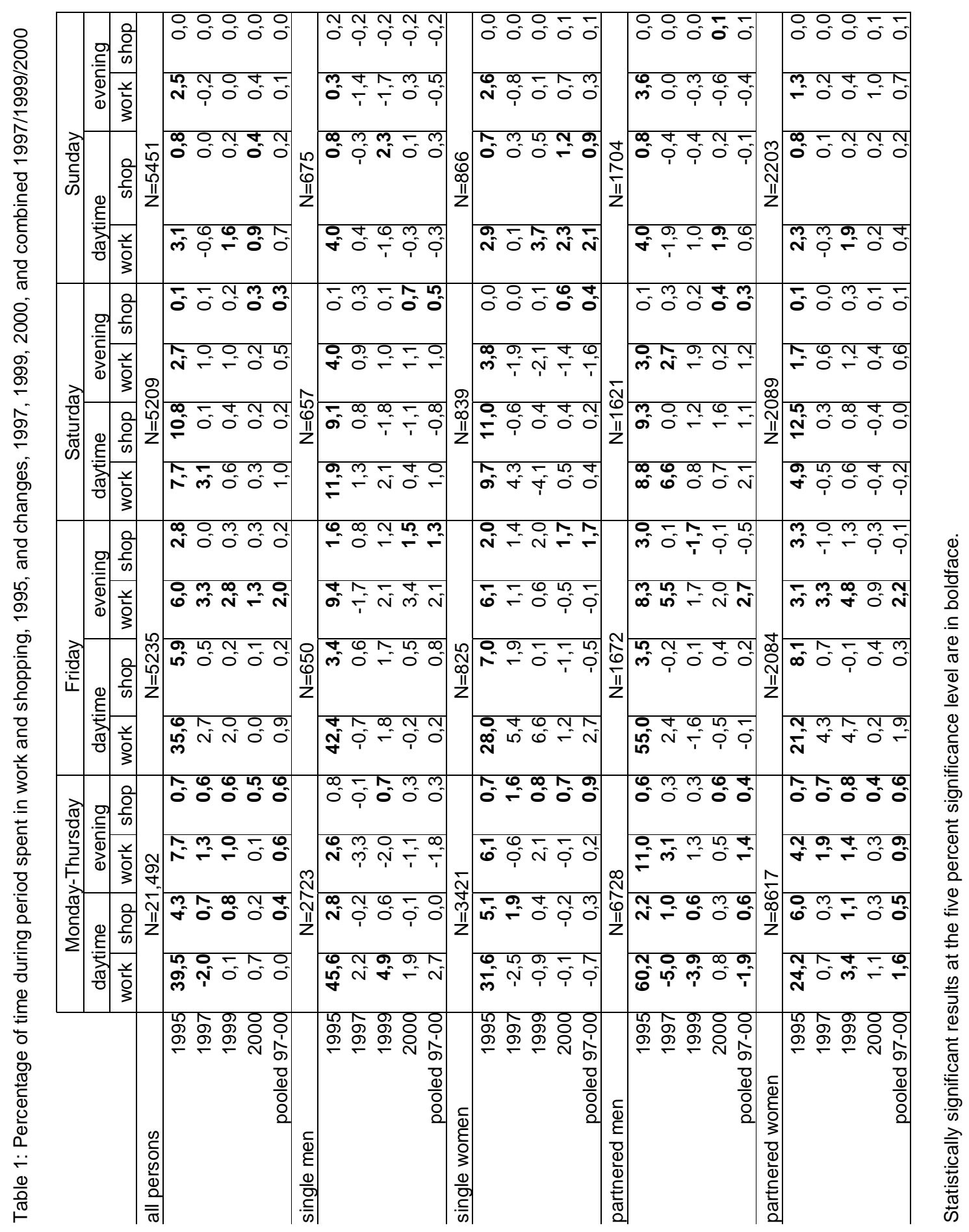


Table 2: Percentage of time during period spent in work and shopping, 1995, and changes, 1997, 1999, 2000, and combined 97/99/00, single full-time workers only

\begin{tabular}{|c|c|c|c|c|c|c|c|c|}
\hline & \multicolumn{4}{|c|}{ Monday-Thursday } & \multicolumn{4}{|c|}{ Friday } \\
\hline & \multicolumn{2}{|c|}{ daytime } & \multicolumn{2}{|c|}{ evening } & \multicolumn{2}{|c|}{ daytime } & \multicolumn{2}{|c|}{ evening } \\
\hline & work & shop & work & shop & work & shop & work & shop \\
\hline all & \multicolumn{4}{|c|}{$\mathrm{N}=2198$} & \multicolumn{4}{|c|}{$\mathrm{N}=468$} \\
\hline 1995 & 90,0 & 1,2 & 12,9 & 1,2 & 89,4 & 1,5 & 10,8 & 3,2 \\
\hline 1997 & $-0,8$ & 0,2 & $-2,4$ & 0,2 & $-0,9$ & 0,0 & $-1,0$ & 3,8 \\
\hline 1999 & 0,9 & $-0,3$ & $-0,3$ & 1,4 & 1,7 & 0,4 & 4,4 & 1,2 \\
\hline 2000 & 0,2 & $-0,3$ & $-1,7$ & 0,4 & 0,2 & $-0,6$ & $-1,9$ & 1,8 \\
\hline pooled $97-00$ & 0,2 & $-0,2$ & $-1,5$ & 0,6 & 0,3 & $-0,3$ & $-0,6$ & 2,0 \\
\hline men & \multicolumn{4}{|c|}{$\mathrm{N}=1227$} & \multicolumn{4}{|c|}{$\mathrm{N}=252$} \\
\hline 1995 & 90,5 & 0,9 & 14,6 & 1,0 & 90,5 & 0,9 & 14,6 & 1,0 \\
\hline 1997 & $-2,1$ & 0,2 & $-3,1$ & $-0,4$ & 0,0 & $-0,5$ & $-1,5$ & 1,6 \\
\hline 1999 & 0,4 & $-0,4$ & $-2,0$ & 1,4 & 0,5 & 0,8 & 6,2 & 0,0 \\
\hline 2000 & 0,4 & $-0,2$ & 0,7 & 0,5 & 1,0 & $-0,9$ & 1,1 & 1,4 \\
\hline pooled 97-00 & $-0,1$ & $-0,2$ & $-0,8$ & 0,6 & 0,7 & $-0,5$ & 1,8 & 1,1 \\
\hline women & \multicolumn{4}{|c|}{$\mathrm{N}=970$} & \multicolumn{4}{|c|}{$\mathrm{N}=215$} \\
\hline 1995 & 89,4 & 1,5 & 10,9 & 1,5 & 89,7 & 1,4 & 10,2 & 2,8 \\
\hline 1997 & 1,2 & 0,3 & $-2,3$ & 1,4 & $-2,0$ & 0,8 & $-0,6$ & 6,8 \\
\hline 1999 & 1,6 & 0,1 & 1,6 & 1,4 & 3,2 & $-0,3$ & 2,2 & 3,2 \\
\hline 2000 & 0,0 & $-0,5$ & $-3,6$ & 0,3 & $-0,4$ & $-0,4$ & $-4,8$ & 1,9 \\
\hline pooled 97-00 & 0,5 & $-0,3$ & $-2,5$ & 0,6 & 0,0 & $-0,2$ & $-3,0$ & 2,8 \\
\hline
\end{tabular}

Statistically significant results at the five percent significance level are in boldface. 
Table 3: Means, Standard Deviations, and Number of Observations for Routine, 1995 and 2000, overall and by demographic subsample

\begin{tabular}{|c|c|c|c|c|c|}
\hline & $\begin{array}{c}\text { all } \\
\text { persons }\end{array}$ & $\begin{array}{c}\text { single } \\
\text { men }\end{array}$ & $\begin{array}{l}\text { single } \\
\text { women }\end{array}$ & $\begin{array}{l}\text { partnered } \\
\text { men }\end{array}$ & $\begin{array}{l}\text { partnered } \\
\text { women }\end{array}$ \\
\hline \multicolumn{6}{|l|}{ weekdays } \\
\hline 1995 & $\begin{array}{c}\text {,598 } \\
(.127) \\
2725\end{array}$ & $\begin{array}{c}632 \\
(.146) \\
338\end{array}$ & $\begin{array}{c}.574 \\
(.120) \\
415\end{array}$ & $\begin{array}{c}655 \\
(.131) \\
870\end{array}$ & $\begin{array}{c}.553 \\
(.097) \\
1102\end{array}$ \\
\hline 2000 & $\begin{array}{c}, 594 \\
(.130) \\
1459 \\
\end{array}$ & $\begin{array}{c}, 631 \\
(.155) \\
183 \\
\end{array}$ & $\begin{array}{c}, 569 \\
(.119) \\
280 \\
\end{array}$ & $\begin{array}{c}, 661 \\
(.134) \\
396 \\
\end{array}$ & $\begin{array}{c}, 551 \\
(.100) \\
600 \\
\end{array}$ \\
\hline \multicolumn{6}{|l|}{ weekends } \\
\hline 1995 & $\begin{array}{c}.460 \\
(.122) \\
2725\end{array}$ & $\begin{array}{c}\text {,435 } \\
(.143) \\
338\end{array}$ & $\begin{array}{c}, 466 \\
(.125) \\
415\end{array}$ & $\begin{array}{c}458 \\
(.128) \\
870\end{array}$ & $\begin{array}{c}\text {,466 } \\
(.109) \\
1102\end{array}$ \\
\hline 2000 & $\begin{array}{c}, 466 \\
(.126) \\
1459\end{array}$ & $\begin{array}{c}, 456 \\
(.155) \\
183\end{array}$ & $\begin{array}{c}, 446 \\
(.136) \\
280\end{array}$ & $\begin{array}{c}, 467 \\
(.122) \\
396\end{array}$ & $\begin{array}{c}, 479 \\
(.112) \\
600\end{array}$ \\
\hline
\end{tabular}

